\title{
SRP and ENSP - an exceptional common manifestation
}

\section{(2) The $4^{\text {th }}$ ENSP-SRP International ENSP SRP Conference on Tobacco Control Bucharest 27-29 March 2019}

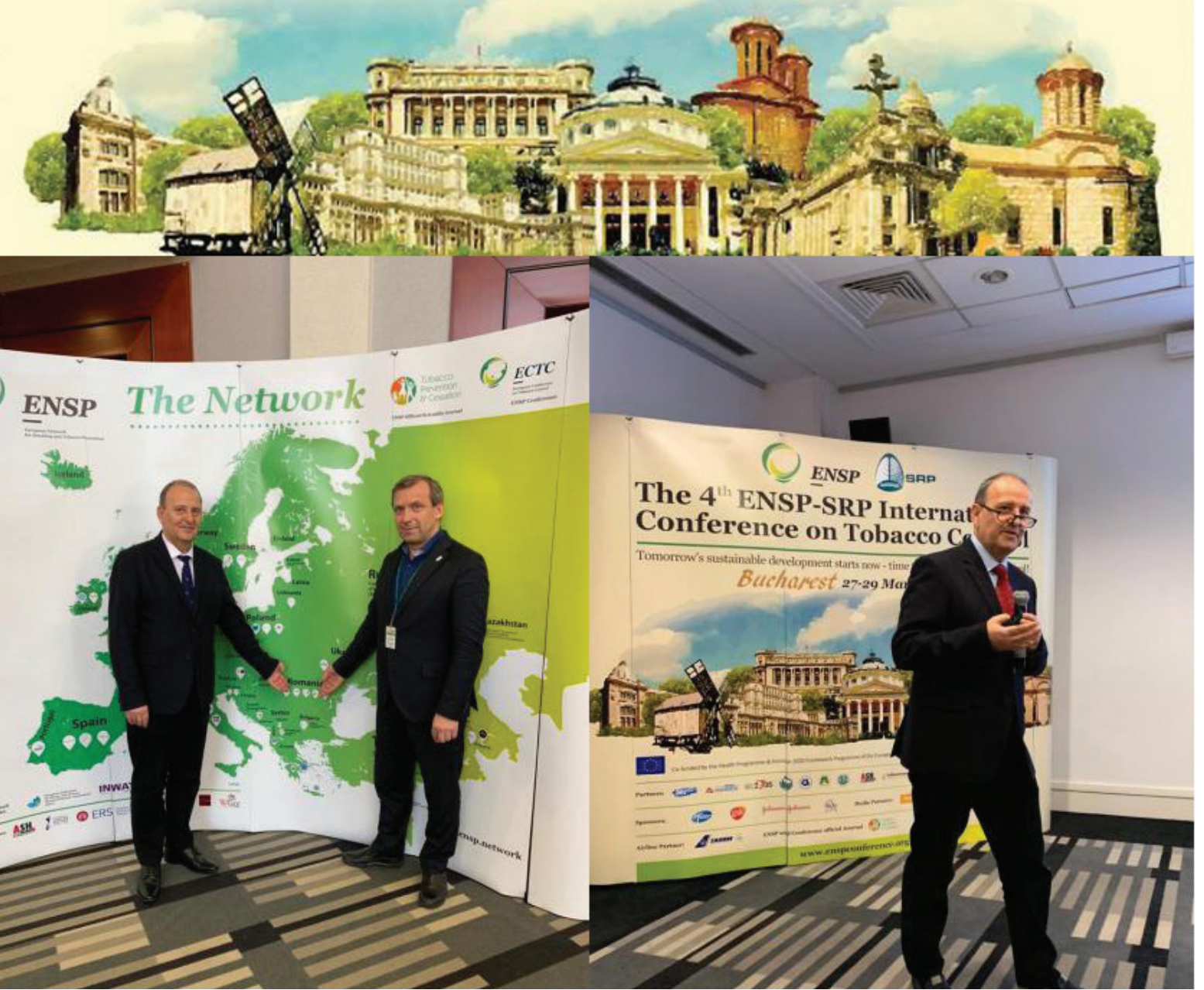

${ }^{*}$ Corresponding author: Florin Mihălțan E-mail:mihaltan@starnets.ro 


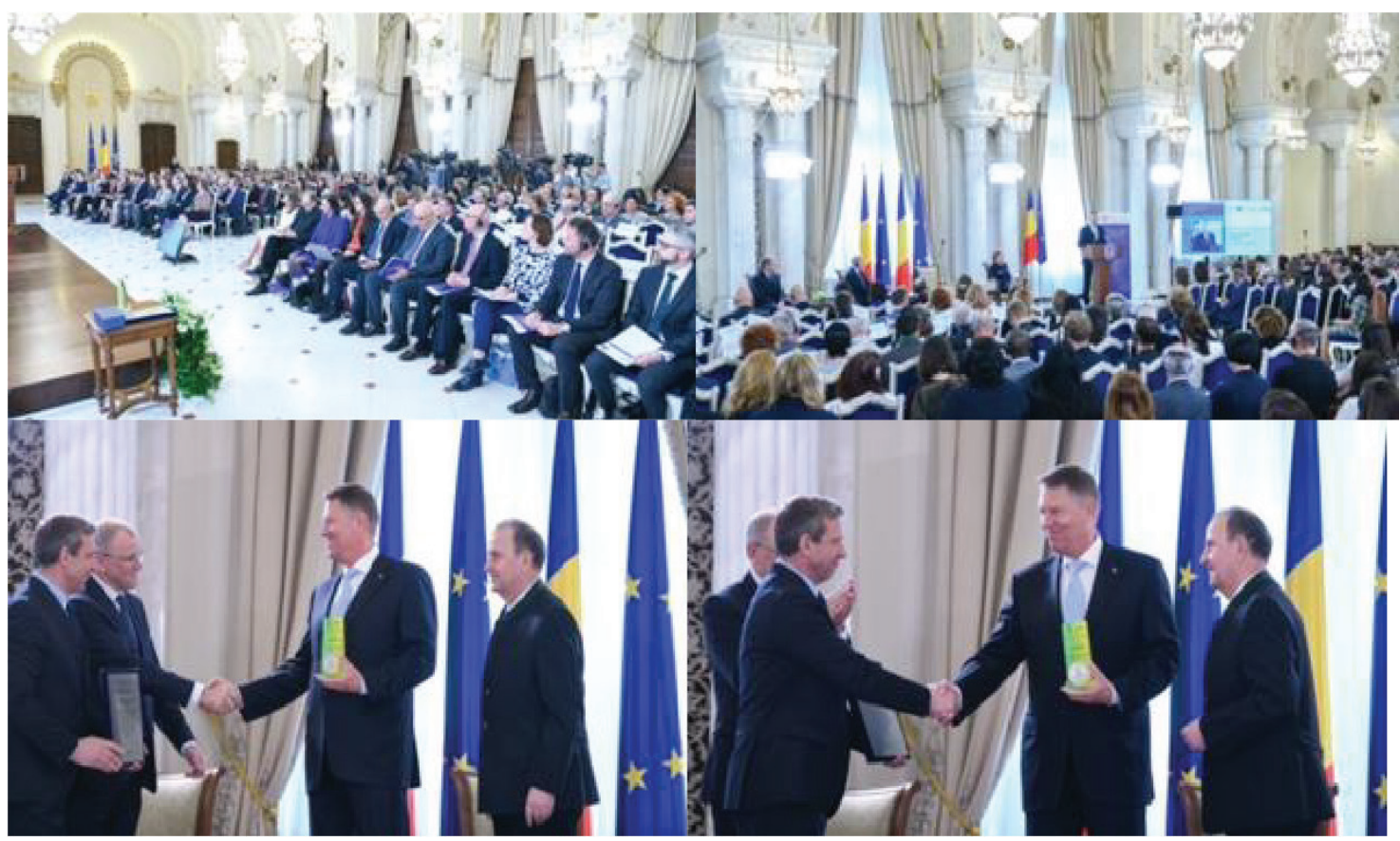

From 27 to 29 March 2019, Bucharest hosted the 4th International Conference of the ENSP and the national conference of the $\mathrm{SRP}$ on tobacco control issues. The preamble to this event was created by an expert meeting on 26 March 2019 at the "Global Human Rights Forum and a World without Tobacco" chaired by the President of Romania at the Cotroceni Palace. The President of our country Mr Klaus Werner lohannis showed on this occasion that how preventive work can be supported, the progress made in our country underlining the important mission of all those involved in the control of smoking. On this occasion, talked a large number of guests, such as Vytenis Andriukaitis, European Commissioner for Health and Food Safety, a renowned opponent of the smoking and tobacco industry who pointed out the dangers posed by this industry for the health of nations emphasising the need for radical interventions in this area, including their elimination from sale, to stop its consequences on the health of nations. Interventions in favour of tobacco control also came from a guest of honour, Princess Dina Mired of the Hashemite Kingdom of Jordan, Prof Ildiko Horvath - the Secretary of State for Health of Hungary, etc. Each of them pointed out the long way to go in trying to correct the anti-smoking legislation. They were joined by video interventions of Uruguayan President Tabaré Ramón Vázquez Rosas and Dr Vera Luiza Da Costa e Silva, the Head of the Secretariat WHO-FCTC, which marked the necessary way for each nation to stop the tobacco industry's actions that have an impact on their health.

At this event, the "European Network for Smoking Prevention" and the "Romanian Pneumology Society" awarded the President of our country with a degree of recognition of his merits and for how he encouraged the anti-smoking activities.

The next 3 days were dedicated to the scientific activities organised at the subsequent international conference which were held at the same time as the national smoking conference with international participation. Attendance was above expectations: 50 countries represented by non-governmental organisations and professional associations and 400 international experts.

The Romanian presence was not lower either. Impressive for guests was the high percentage of young people who were in the rooms, many of them being medical students. The themes have been of a variety and diversity that only such an event can achieve, being anchored in all the policy changes of the tobacco industry in recent years and also in "policy and advocacy" that marks the path of non-governmental organisations. The event took place simultaneously in four rooms and covered topics from all areas of tobacco control, such as "youth people and tobacco", "EU actions in tobacco control", "international and national tobacco control activities", "taxation and related prices of heated tobacco", "illicit tobacco trafficking", "creating bridges between tobacco taxation and effective taxation policies", "an overview of heated tobacco", "women's voice in tobacco control in Europe", "nicotine addiction", "media, sport and tobacco consumption", "treatment of nicotine addiction", "electronic cigarettes and new tobacco products", etc. There have also been a number of absolute premieres such as a session of the nurses from Europe as well as from Romania and Moldova, the ERS-ENSP symposium and the one announcing the results of the EUREST projects (where ENSP was the leading actor), the comparison of the legislative strategies in the Balkans, and also the establishment of a panel of dentists that will initiate specific anti-smoking actions.

The Romanian experts were present with interesting exposures throughout the conference; they split both the progress in the tobacco control field and the failures, the limits of these activities. Throughout the event, an enthusiastic team of medical students made the "offices" of the house. The conference has the merit of allowing Bucharest for 3 days in the Romanian and international media to be recognised as a world capital of the anti-smoking fight. The way of organising has been appreciated by everyone from leading invitations from international and global organisations to representatives of different international organisations. This fourth international conference also highlighted an important element: "European Network for Smoking Prevention" once again proved the progress of this association, which from 1 year to the next has an increasingly difficult word to say in the fight against smoking worldwide. 